\title{
Development of a boarding and alighting time model for the urban rail transit in a megacity
}

\author{
J. Kim ${ }^{1}$, M. S. Kim ${ }^{1}$, J. S. Hong ${ }^{1} \&$ T. Kim ${ }^{2}$ \\ ${ }^{1}$ Korea Railroad Research Institute, Korea \\ ${ }^{2}$ Department of Civil Engineering, Hongik University, Korea
}

\begin{abstract}
Dwell time is the time a loaded rail transit spends in a station, which consists of operation time, standby time, and passenger flow time. Among these, passenger flow time, the time required by passengers to board and alight (i.e., boarding and alighting time), is the key factor that determines the dwell time. Wide fluctuations in boarding and alighting time are found in crowded urban areas, especially in a megacity such as Seoul. Accordingly, it is very important to accurately assess the boarding and alighting time for the efficient scheduling of an urban rail transit. Numerous studies have been conducted to develop the prediction model in many countries. However, most of the suggested models were developed based on the light rail transit, so it may not be appropriate to apply those models to the heavy rail transit that is mainly running in Seoul. Furthermore, the passenger behaviour, which is one of the key influencing factors, varies depending upon behavioural devices such as bleepers, indicating that doors are closing or platform screen door, etc. Hence, the existing models developed under different circumstances cannot be applied blindly to the assessment, and the limitation of those models should be evaluated. In this study, existing models are evaluated by the regression analysis of data measured in Seoul metro green-line. Then, a novel boarding and alighting time model is proposed. The superior performance of the proposed model is demonstrated by comparing the adjusted coefficient of determination. This model can be employed to schedule train operation as well as to assess time consumption if the boarding and alighting passengers are given.
\end{abstract}

Keywords: urban rail transit, boarding and alighting time, dwell time, efficient scheduling, megacity. 


\section{Introduction}

Urban rail transit is one of the most important transportation and plays a major role of both inbound and outbound traffics as well as city traffics. The modal shares of the urban rail transit in world cities such Paris, New York and Tokyo exceed fifty percent if walking is excluded [1]. A number of researchers have been studied to increase the efficiency of the urban rail transit. They focused on the improvement of the signal system or the reduction of the train headway in order to increase the line capacity [2]. The other major factor that affects the line capacity is dwell time that is the amount of time taken at a station for a train to stop and to start [3]. The dwell time affects the train headway. Accordingly, it should be considered thoroughly to schedule the line operation. It consists of operation time, standby time, and passenger flow time [4]. Operation time is the amount of time to operate functions such as door open and close and standby time is the amount of time for waiting the departure signal. Passenger flow time is the time required by passenger to board and alight, also known as boarding and alighting time. (In this study, we use the boarding and alighting time.) The boarding and alighting time occupies the largest part of dwell time, especially in a megacity such as Seoul. Therefore, it is necessary to assess the boarding and alighting time for each station to improve the efficiency of train scheduling. Hence, the model that can describe the large number of passengers' boarding and alighting time should be developed in order to accurately schedule a busy rail line in a megacity.

A number of studies concerning the boarding and alighting time focused on many parameters such as the number of flowing passengers, the size of gap between the platform and the vehicle, the internal space in the vehicle, and the door width [5]. These parameters are included into the boarding and alighting time model in different forms by country and by line $[2,6]$. These differences result from not only the differences in the specifications of the train and the platform but also the differences in human behaviours. Therefore, the boarding and alighting time model based on a certain country or a line cannot be applied blindly to the other cases [7].

Among many megacities in the world, Seoul is a noticeable megacity because of its high population density and the high crowdedness in the urban rail transit. More than ten million people live in Seoul and approximately twenty five million people live in the Seoul capital area, which includes the surrounding Incheon metropolis and Gyeonggi province. Seoul is the largest city proper and has the highest population density in the OECD [8]. It has the world third highest population density and the world second largest metropolitan area $[9,10]$. In Seoul, nine urban transit lines are in operation and the degree of crowdedness (DOC) of the busiest lines (green line and golden line) exceeds two hundred percent. Accordingly, many plans to increase the line capacity and to alleviate the crowdedness are being considered and implemented.

The purpose of this study is to develop the boarding and alighting time model of the urban rail transit in Seoul. In the literature review, we briefly summarize the existing models and discussed their limitations. Thereafter, we explain the data 
acquisition method for this study and proposed a novel boarding and alighting time model. The model fidelity is demonstrated by comparing the adjusted coefficient of determination of the proposed model with those from the previous models.

\section{Literature review}

First, the boarding and alighting time model proposed in the early stage is based on the linear equation that is composed of the number of boarding, alighting, and on-board passengers. Studies on the linear model focused to find the linear coefficient that fits the measured or simulated data. Lin and Wilson [11] formed the linear model according to the number of boarding, alighting, and on-board passengers after analysing the dwell time data at the MBTA (Massachusetts Bay Transportation Authority) Green Line LRT (Light Rail Transit). Puong [12] formed a linear model from the MBTA Red line data. Both models have a common feature that used the data acquired at the LRT where the boarding and alighting passengers are generally fewer than those in the normal urban rail transit, and hence, the analysis is relatively plain. Besides Lin and Wilson [11] and Puong [12], there have been studies [3, 4, 13, 14] that used LRT data. It is noteworthy that Parkinson and Fisher [4] proposed the exponential model rather than linear model. It considered that the boarding and alighting time was increased exponentially as the car was more crowded. However, this model can be applied only if the number of boarding and alighting passengers is less than 25 respectively.

It is known that the fractional square model proposed by Weston [15] is widely fits on the normal urban rail transit [7]. The Weston model is based on the fact that the boarding or alighting time per a person is decreased because the passengers can board or alight successively in a line if the number of boarding and alighting passengers is sufficiently large. Harris [16] disclosed that the coefficient of crossing passengers in the Weston model was designated excessively and proposed a revised fractional square model after analysing data acquired from the South West Train, United Kingdom, and proposed the new fractional square model. However, it was shown that the Weston model can be applied internationally if some of the coefficients are properly adapted [7]. In [7], the worldwide dwell time data acquired by benchmarking groups such as the CoMET and Nova Metro was used for the comparison. Even though these benchmarking groups contain data from various continents, they do not have the Seoul metro data. Although Kim et al. [17] found coefficients for the fractional model [16] suitable to the measured data in Korea, it is necessary to find more suitable model to the boarding and alighting time in Seoul.

\section{Data acquisition}

It is very important to acquire the data accurately to develop the boarding and alighting time model. In this chapter, we review various methods of data acquisition. Then, the information regarding the target rail transit line and Seoul is briefly introduced. 


\subsection{Methods of data acquisition}

The boarding and alighting time of the passengers can be obtained by two different methods. The first one is to obtain the actual operation data. This acquisition can be performed by gathering the logged data of the train spending time at the station from the operating companies $[2,7,15]$ or by analysing the video clips recorded at the stations. This method has advantages that can acquire the real data. However, it has the limitations when conducting the parametric studies due to its uncontrollable circumstance. For example, the door width in the Korean urban rail transit is fixed to $1,300 \mathrm{~mm}$. The influence of the various door widths on the passenger flow cannot be investigated with the real data. It is well known that DOC is one of the most influencing factors that determines the boarding and alighting time, but it is impossible to count accurately the number of passengers inside the crowded car from the video clips. In addition, the boarding and alighting time cannot be obtained from the logged data of the train spending time at the station, because the data usually contains the dwell time not the actual boarding and alighting time. Even though some logged data contain the door operation time [2], trains can wait the start signal with its door open, so there is difference between the logged door open time and the actual boarding and alighting time.

The second method is the experimental simulation. With the mock-up car, the boarding and alighting time of the participants who play the role of passengers can be measured $[5,6,16]$. With this experimental simulation, the relations between the time and the influencing factors can be found. However, it is not the actual situation, so the participants may act differently from the real case because they act under the influence of experimental situation.

In this study, the video clips recorded at the stations were carefully investigated to accurately obtain the actual boarding and alighting time as opposed to the door open time or the dwell time.

\subsection{Measurement description}

The target is the green line which is one of the busiest lines in Seoul. This line is a circular line that connects other lines and passes through many popular places in Seoul. The average number of passengers in a day is more than two million and the maximum DOC is $230 \%$ [18]. Figure 1 shows the route of green line and the boundary of Seoul. The official name of the green line is Seoul subway line 2. The total length of the green line is $48.8 \mathrm{~km}$ without two branch lines and the number of stations is 44 .

The measurement was performed in peak periods both in the morning (7:30 8:30) and in the evening (18:00-19:00) as well as in off-peak periods (10:00-11:00, 15:00-16:00). The targets are the stations located in the south half of the circle, from Sindorim to Samseong, where the line capacity is full in the morning busy hour. More than 10 video clips per every station were recorded and totally 261 boarding and alighting time data were gathered. The methods of the measurement are as follows: 


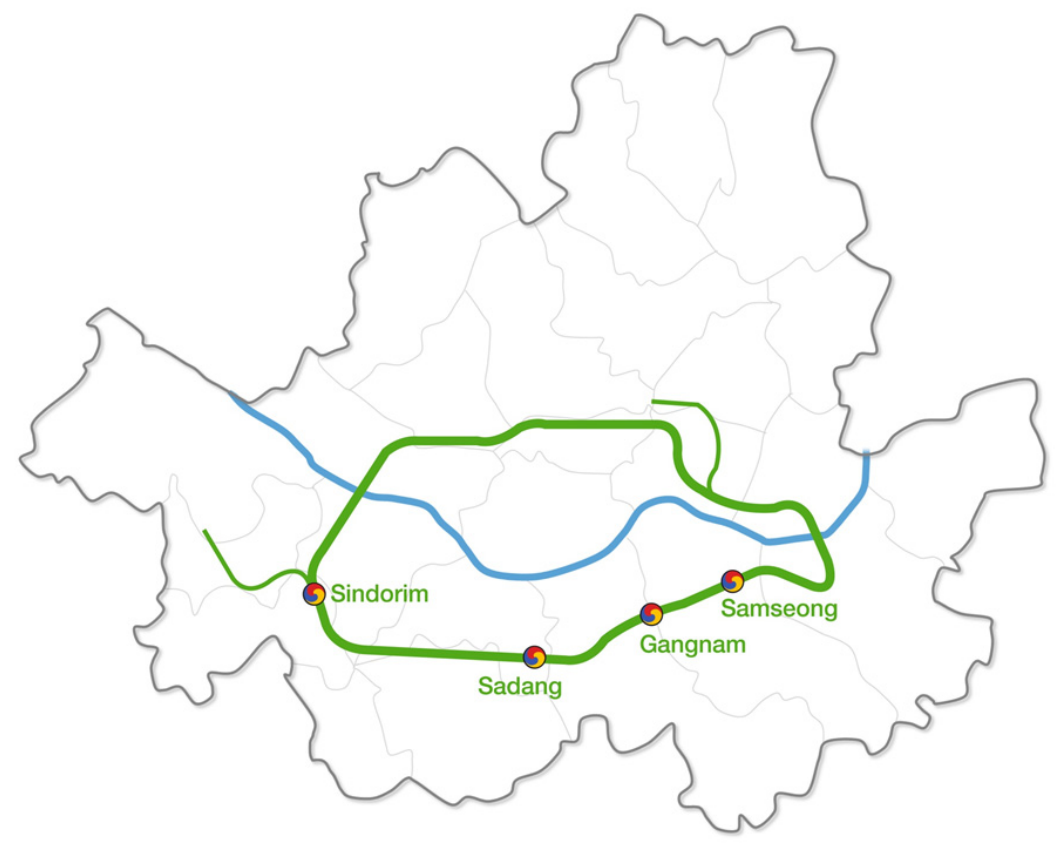

Figure 1: $\quad$ The route of green line and the boundary of Seoul.

(1) The busiest door, typically the one nearest to the stairs or the transfer passage was chosen for the video record. The dwell time is mostly influenced by the boarding and alighting time at the busiest door.

(2) The passenger flows were recorded from train stop to start. Then, the numbers of boarding and alighting passengers were counted from the video clips.

(3) The boarding and alighting time also was measured from the video clips. In this study, the boarding and alighting time was defined as the time from the completion of the door open to the completion of boarding of clustered boarder in order to exclude non-clustered boarder's boarding time. Note that the distribution of that is atypical [19].

(4) We did not separate the boarding time and the alighting time because the boarding was started before the alighting was finished in most cases.

(5) The DOC is defined as the ratio of the number of on-board passengers in a car to the capacity. However, as described earlier, it is hard to count the accurate number of on-board passengers especially in a crowded car. Therefore, we used the Korail (Korea Railroad Corporation) standard for assessing the DOC which is listed in table 1.

Figure 2 shows a typical scene of the boarding and alighting captured from the video clip. It was recorded at the Gangnam station which is one of the busiest stations in the green line. 
Table 1: $\quad$ Korail standard for the degree of crowdedness $[20]^{1}$.

\begin{tabular}{|c|l|c|}
\hline $\begin{array}{c}\text { Degree } \\
\text { number }\end{array}$ & \multicolumn{1}{|c|}{ State description } & $\begin{array}{c}\text { DOC } \\
(\%)\end{array}$ \\
\hline 1 & Five persons are sit in a row of seats & 24 \\
\hline 2 & $\begin{array}{l}\text { All seats are occupied (seven persons are sit in a row of } \\
\text { seats). }\end{array}$ & 34 \\
\hline 3 & $\begin{array}{l}\text { Degree 2 + Five persons are standing in front of each row of } \\
\text { seats }\end{array}$ & 59 \\
\hline 4 & Degree 3 + Two persons are standing per each door. & 75 \\
\hline 5 & All seats and handles are occupied. & - \\
\hline 6 & Degree 5 + Two persons are standing per each door. & 100 \\
\hline 7 & $\begin{array}{l}\text { Degree 5 + Additional line of persons are standing in a } \\
\text { vestibule (centre area between opposite two doors) }\end{array}$ & - \\
\hline 8 & $\begin{array}{l}\text { Degree 7 + Two persons are standing per each door. } \\
\text { Degree 7 + Six persons are standing per each door. }\end{array}$ & 115 \\
\hline 10 & $\begin{array}{l}\text { Degree 5 + Additional two lines of persons are standing in a } \\
\text { vestibule. And eight persons are standing per each door. }\end{array}$ & 150 \\
\hline 11 & $\begin{array}{l}\text { Degree 5 + Additional three lines of persons are standing in } \\
\text { a vestibule. And eight persons are standing per each door. }\end{array}$ & 175 \\
\hline 12 & $\begin{array}{l}\text { Degree 5 + Additional three lines of persons are standing in } \\
\text { a vestibule. And ten persons are standing per each door. }\end{array}$ & 200 \\
\hline 13 & Degree 12 + Passengers are stuck together. No space in a car & 230 \\
\hline
\end{tabular}

Note 1: The state descriptions for the DOC $250 \%$ and $270 \%$ were omitted because these values exceed the maximum DOC of the green line.

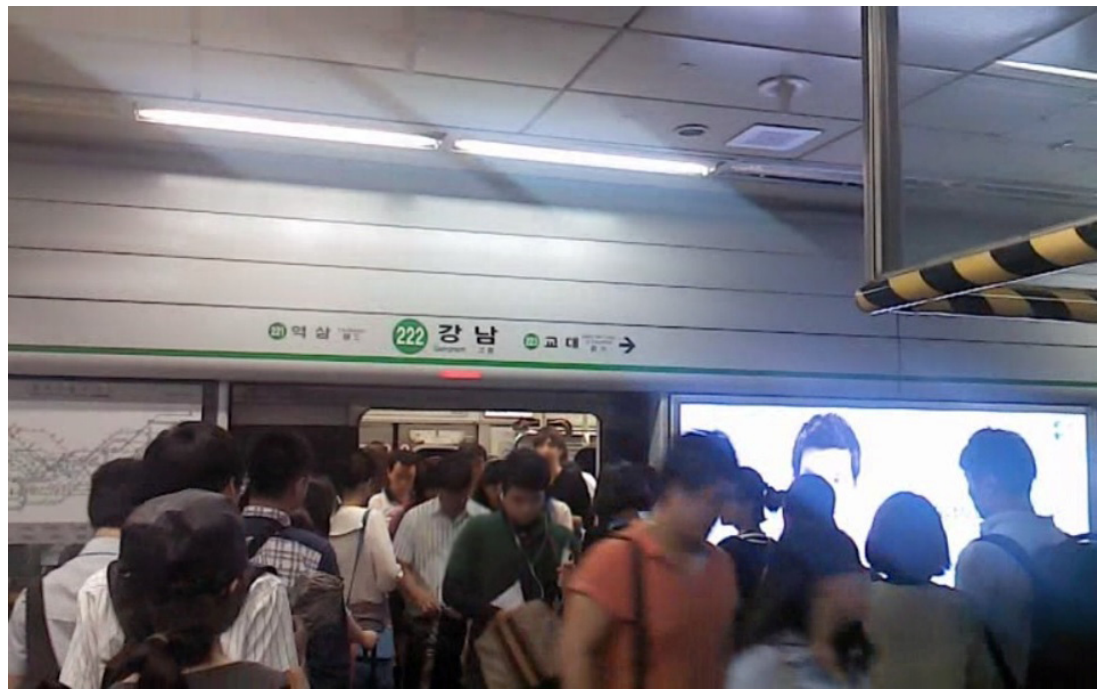

Figure 2: A typical scene of a video clip that was recorded for measuring the time and the number of passengers boarding and alighting. 
Table 2: Previous model equations and their performance.

\begin{tabular}{|c|c|c|c|}
\hline Model & Equation $^{2}$ & $\bar{R}^{2}$ & $\begin{array}{c}\text { Sum } \\
\text { of } \\
\text { error }^{2}\end{array}$ \\
\hline Linear [11] & $\begin{array}{c}T_{a b}=0.4573 P_{a}+0.6161 P_{b}+ \\
3.1545 \cdot D O C+0.3517\end{array}$ & 0.9345 & 1297.8 \\
\hline Polynomial [12] & $\begin{array}{c}T_{a b}=0.4237 P_{a}+0.6267 P_{b}+ \\
0.0212 P_{b} \cdot D O C^{3}+3.5710\end{array}$ & 0.9164 & 1655.1 \\
\hline Exponential [4] & $\begin{array}{c}T_{a b}=\exp \left(0.0486 P_{a}-0.00066 P_{a}^{2}+\right. \\
0.0624 P_{b}-0.00104 P_{b}^{2}+0.2225 \cdot \\
D O C+1.4972)\end{array}$ & 0.9124 & 1736.7 \\
\hline $\begin{array}{c}\text { Fractional } \\
\text { square [16] }\end{array}$ & $\begin{array}{c}T_{a b}=1.1234\left(P_{a}^{0.7976}+P_{b}^{0.8514}\right)- \\
0.0047 P_{a} P_{b}+3.4207 \cdot D O C-2.7453\end{array}$ & 0.9474 & 1033.9 \\
\hline
\end{tabular}

Note 2: $T_{a b}$ : the boarding and alighting time, $P_{a}$ : the number of alighting passengers, $P_{b}$ : the number of boarding passenger, and $D O C$ : the degree of crowdedness.

\section{Model development}

In this section, the boarding and alighting time model is proposed based on the measured data. First, the fidelities of the existing models are investigated with regression method. Then, a new model is proposed by revising the existing models via the residual analysis. The performance of the proposed model is also evaluated by comparing the adjusted coefficients of determination with the existing models.

\subsection{Fidelity investigation of the previous models}

Four of existing models were investigated to evaluate the fidelity. The coefficients of each model were determined by the regression method with the measured data in the sense of minimum least square of errors, and these equations are shown in table 2. The adjusted coefficients of determination $\left(\bar{R}^{2}\right)$ of each model are also shown for the performance comparison. Figure 3 shows the graph of the boarding and alighting time variation with the number of boarding passengers. The measured time is also presented in figure 3 . All the evaluated models show relatively high $\bar{R}^{2}$ greater than 0.9 . The fractional square model [16] presents the highest $\bar{R}^{2}$, but exponential model [4] presents the lowest. This is obvious because exponential model cannot be applied to the case that the numbers of boarding or alighting passengers exceed 25 .

\subsection{Regression analysis}

The residuals computed from the fractional square model with the highest $\bar{R}^{2}$ versus DOC are plotted in figure 4 . The curve shape of the average of the residuals is a concave up. This implies that the term for the DOC was not determined correctly, and a higher degree term of the DOC should be added for the better model [21]. 


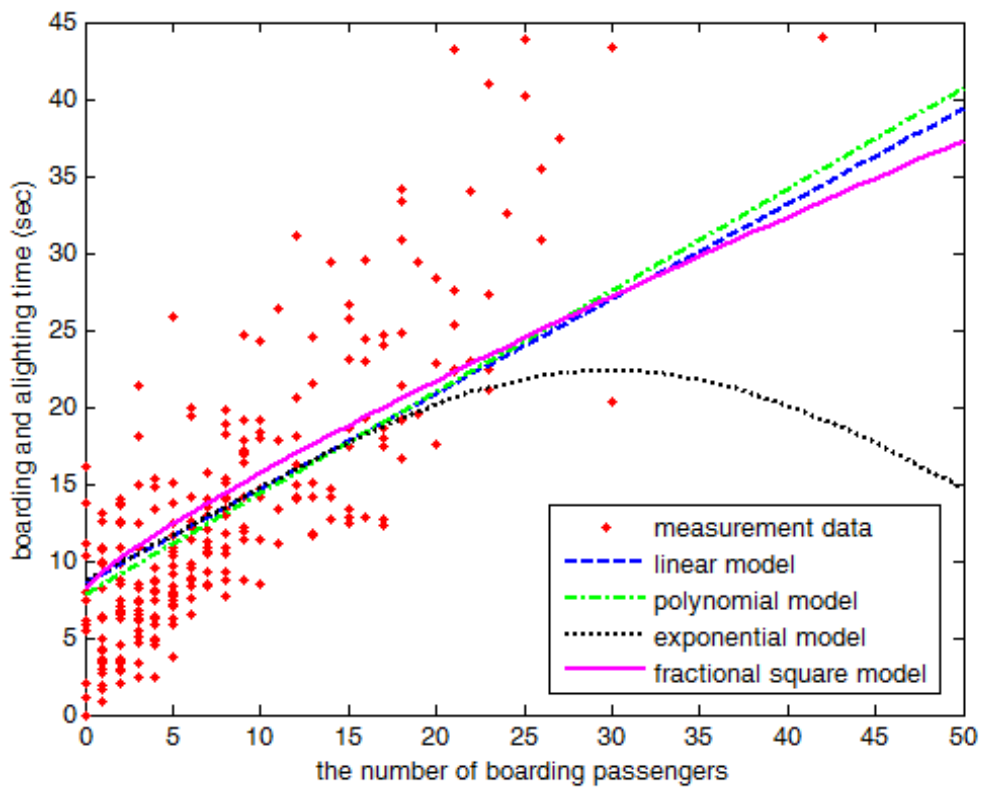

Figure 3: The boarding and alighting time variation with the number of boarding passengers (the number of alighting passengers and the DOC are assumed to be 10 and $115 \%$, respectively) with measured data.

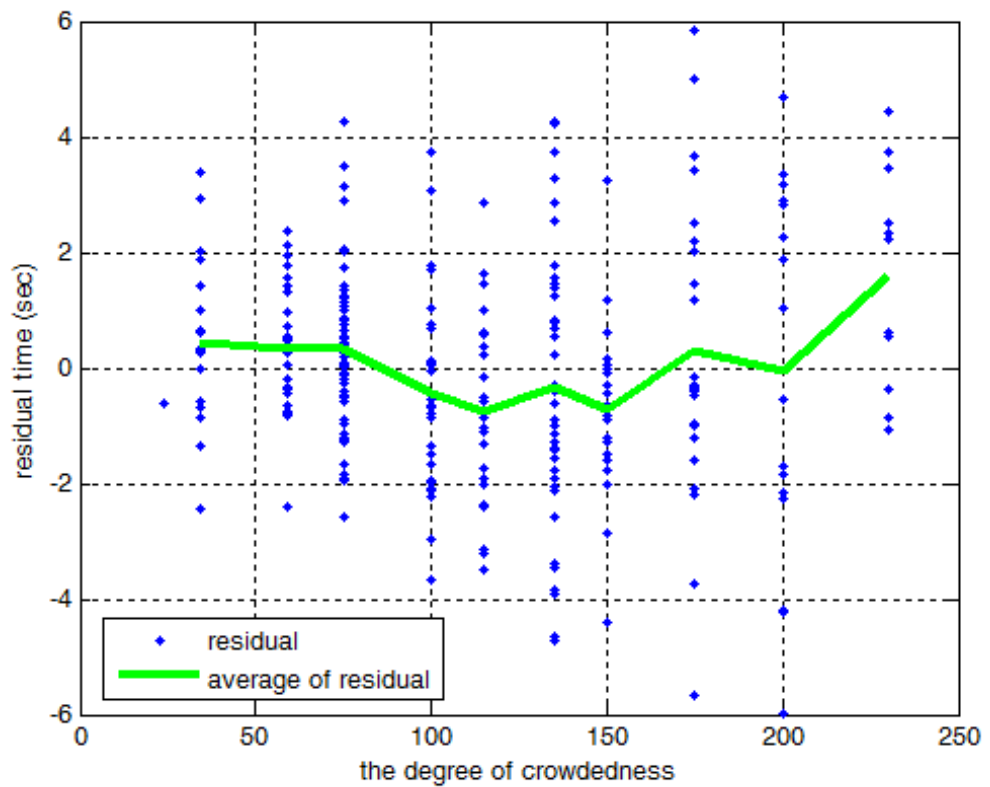

Figure 4: Residuals according to the DOC of the fractional square model. 


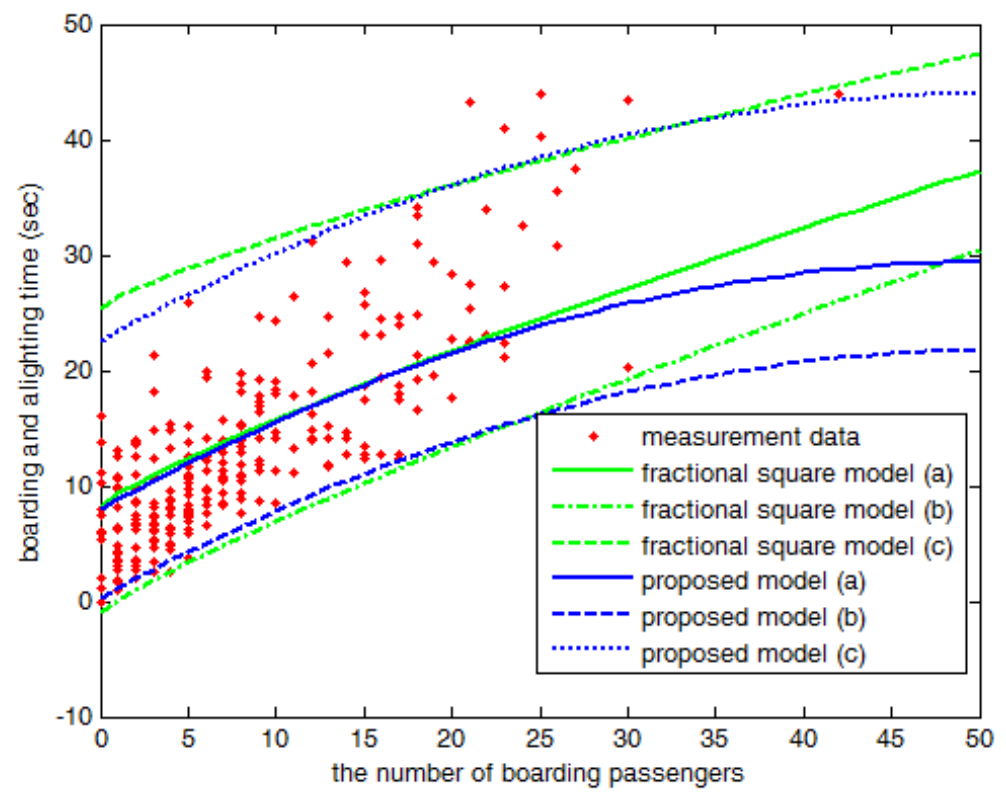

Figure 5: The graph of the proposed model and the fractional square model. (a): nominal case $\left(P_{a}=10, D O C=115 \%\right)$, (b): vacant case $\left(P_{a}=0\right.$, $D O C=50 \%)$, (c): crowded case $\left(P_{a}=40, D O C=200 \%\right)$.

\subsection{Proposed model}

The proposed model is a polynomial equation using the variables of DOC, the number of alighting passengers $\left(P_{a}\right)$ and boarding passengers $\left(P_{b}\right)$, and expressed as:

$$
\begin{aligned}
T_{a b}= & 0.7021 P_{a}-0.0068 P_{a}^{2}+0.8417 P_{b}-0.0083 P_{b}^{2}+3.7953 . \\
& D O C-2.4495 \cdot D O C^{2}+1.0871 \cdot D^{2} O C^{3}-1.1385
\end{aligned}
$$

The power and the coefficient of the variables were decided by the repeated regression analysis. Though the regression analysis was performed with the fractional square models, we could confirm that the polynomial model fitted better than the fractional square model with higher order term of DOC $\left(\bar{R}^{2}=0.9504\right)$, and this matter is coincidence with the result of the research for impact factors [2]. The adjusted coefficient of determination of the proposed model is 0.9516 which is higher than those of the existing models. The sum of squared error of the proposed model is 944.5 and this denotes the $8.7 \%$ decrease from that of the fractional square model. Figure 5 shows the graph of the proposed model as well as the fractional square model for various cases. 


\section{Conclusions and further works}

The boarding and alighting time model was developed with the measurement data and the regression method. The fractional square model was used whether it agrees with the measured data. However, it was found that higher order term of the DOC can improve the model after conducting a number of the regression analysis. New model using the polynomial equation was proposed in this study. The performance of the proposed model was verified by comparing the adjusted coefficient of determination. In this study, the door width effect is not considered that might largely influence on the boarding and alighting time. To develop a better model, additional experiment with the various door widths is planned. By performing this experiment and developing a model including the door width as a variable, the boarding and alighting time could be accurately predicted. Furthermore, the time reduction effects can be evaluated when the door is enlarged.

\section{References}

[1] Focas, C., (eds). The Four World Cities Transport Study, The Stationery Office, London, pp. 164-171, 1998.

[2] Harris, N.G., Graham, D.J., Anderson, R.J., \& Li, H., The impact of urban rail boarding and alighting factors, TRB 93rd Annual Meeting, Washington, D.C., 2014.

[3] Transportation Research Board, Highway capacity manual 2000, National Research Council, Washington, D.C., 2000.

[4] Parkinson, T. \& Fisher, I., Rail Transit Capacity, Transit Cooperative Research Program Report 13, National Academy Press, Washington, D.C., pp. 38-50, 1996.

[5] Daamen, W., Lee, Y.-C., \& Wiggenraad, P., Boarding and alighting experiments: overview of setup and performance and some preliminary results. Transportation Research Record, (2042), Transportation Research Board of the National Academies, Washington, D.C., pp. 71-81, 2008.

[6] Rowe, I. \& Tyler, N., High Density Boarding and Alighting: A PsychoPhysical Experiment, Proc. of the $3^{\text {rd }}$ International Rail Human Factors Conference, 2008.

[7] Harris, N.G. \& Anderson, R.J., An international comparison of urban rail boarding and alighting rates, Proc. of the Institution of Mechanical Engineers Part F: Journal of Rail and Rapid Transit, (221), 2007.

[8] OECD, OECD Regions at a Glance 2013: OECD Publishing, http://dx.doi.org/10.1787/reg_glance-2013-en

[9] Wikipedia, http://en.wikipedia.org/wiki/Seoul

[10] Statistics Korea: Government Central Statistics Office. Current population of the Seoul National Capital Area, http://www.index.go.kr/potal/main/ EachDtlPageDetail.do?idx cd=2729

[11] Lin, T. \& Wilson, N.H., Dwell time relationships for light rail systems, Transportation Research Record, (1361), Transportation Research Board of the National Academies, Washington, D.C., pp. 287-295, 1992. 
[12] Puong, A., Dwell time model and analysis for the MBTA red line, Massachusetts Institute of Technology, Massachusetts Institute of Technology's Open Course Ware Project Report, 2000.

[13] Lam, W.H.K., Cheung, C.Y., \& Poon, Y.F., A study of train dwelling time at the Hong Kong mass transit railway system, Journal of advanced transportation, 32(3), pp. 285-295, 1998.

[14] Wirasinghe, S C \& Szplett, D., An Investigation of Passenger Interchange and Train Standing Time at LRT Stations: (ii) Estimation of Standing Time, Journal of Advanced Transportation. 18 (1), pp. 13-24, 1984.

[15] Weston, J G., Train Service Model - Technical Guide, London Underground Operational Research Note 89/18, 1989.

[16] Harris, N.G., Train boarding and alighting rates at high passenger loads, Journal of Advanced Transportation, 40(3), pp. 249-263, 2005.

[17] Kim, J., Kim, M.S., Hong, J.S., Cho, Y.H., \& Kim, T., An analysis of boarding and alighting times for urban railway vehicles, Journal of the Korean Society for Railway, 17(3), pp. 210-215, 2014.

[18] The story of metro 2: ' 160 ' or '400', A news article from the MoneyToday, http://www.mt.co.kr/view/mtview.php?type=1\&no=201306101136358669 8 \&outlink $=1$

[19] Wu, J. \& Ma. S., Crowdedness classification method for island platform in metro station, Journal of Transportation Engineering, 139(6), pp. 612-624, 2013.

[20] Jung, Y.-S. \& Kim, M.-H., The research on the adequacy of urban trainset - focus the Jung-ang line for urban, Proceedings of the Conference of the Korean Society for Railway, Jeju, pp. 7-12, 2007.

[21] Draper, N.R. \& Smith, H., Applied Regression Analysis, $3^{\text {rd }}$ ed., John Wiley \& Sons, Inc., New York, pp. 61-66, 1998. 